\title{
2000 CAEP Membership Report
}

$\mathrm{J}^{\mathrm{u}}$ uly 1st 2000 marked the first CAEP census day of the new millennium and hundreds of thousands of people gathered on Parliament Hill in Ottawa to celebrate. The crowd's festive spirit and enthusiastic waving of the CAEP maple leaf hailed another year of strong membership growth. There are now 1,404 CAEP members, 156 (13\%) more than in 1999 (Fig. 1).

More members continue to choose full active membership (Fig. 2). The active membership category grew by $18 \%$ in 2000 . However, reflecting the growing popularity of emergency medicine as a career option, the largest proportionate increases occurred in the student (39\%) and resident (30\%) categories. There are now 235 student and resident members across the country - our future, and nightshift salvation (Fig. 3).

Regionally, the greatest proportionate increase in membership was in Saskatchewan with a $32 \%$ increase, followed by Manitoba with $25 \%$, Nova Scotia with $24 \%$ and Alberta with $21 \%$. Ontario added the greatest number of new members, 88 , a $17 \%$ increase. All other regions of the country had more modest increases or were unchanged (Fig. 4).

\section{Garth Dickinson, MD}

Associate Editor, CJEM

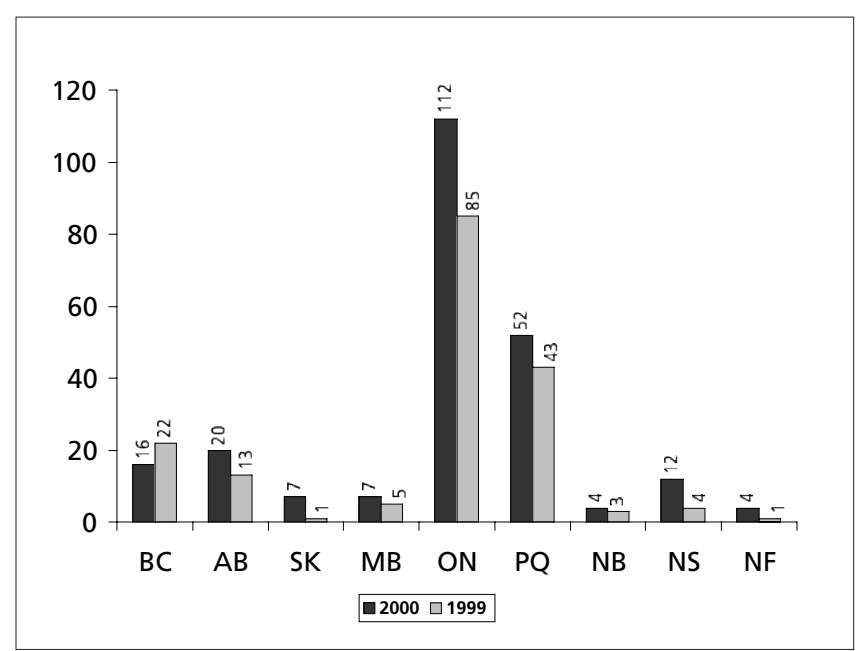

Fig. 3. Residents and students by region

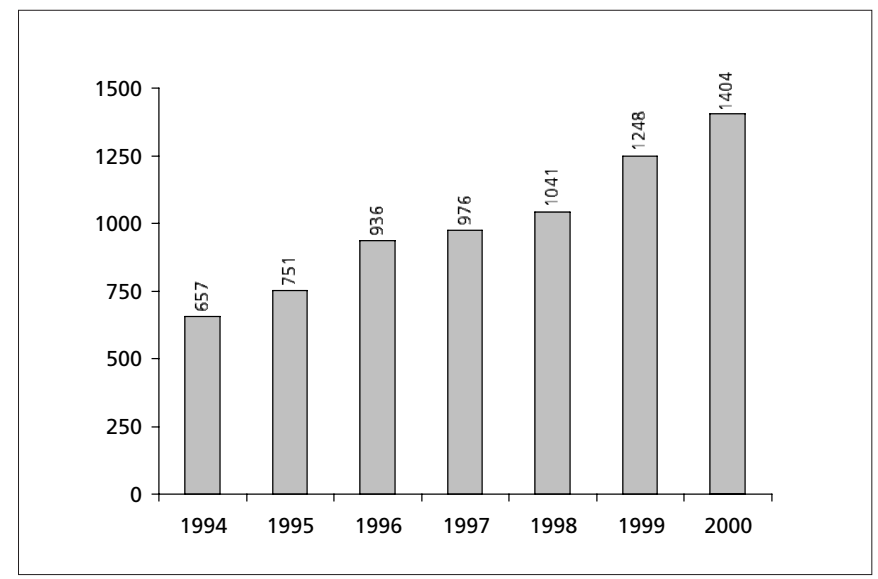

Fig. 1. CAEP membership 1994-2000

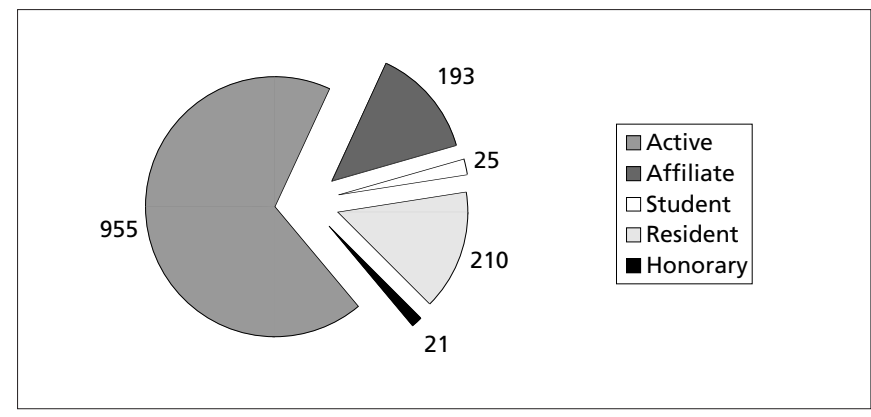

Fig. 2. Membership by category

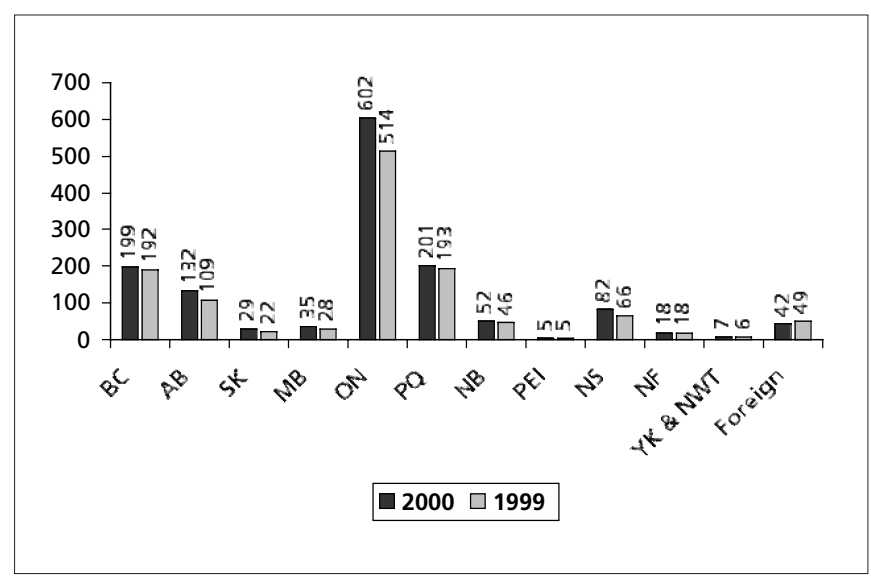

Fig. 4. Regional distribution 


\section{International recognition for Ian Stiell}

$I^{2}$ an Stiell was recently inducted into the Institute of Medicine of the US National Academy of Sciences. Members are chosen for their exceptional professional achievement and commitment to advance health policy issues. The total membership in the Institute is 1,380 and includes several Nobel laureates. When elected in 1999, Ian was one of only 6 new members from outside the United States. In total, there are 56 foreign associate members, and only 3 are from Canada.

This is a great honour for Ian and another milestone in his illustrious career. Ian graduated from medical school at the University of Western Ontario in 1975, completed Family Medicine training at the University of Calgary in 1977, and then completed Emergency Medicine training at McGill in 1980. In 1981, he joined the emergency department at the Ottawa Civic Hospital as a "casualty officer." In the early 1980s, he was dabbling in alphabet soup, adding CFPC, DABEM, FACEP and FRCPC to his name. In the mid- and late eighties, while much of the medical community in Ottawa was engaged in the wasteful politics of "duelling hospitals," Ian wisely chose to focus on research training. In 1991 he received his Masters of Science in Epidemiology from the University of Ottawa. Since that time, his research and publication career has shifted into high gear.

In 1992, his landmark article in the New England Journal of Medicine put to rest years of anecdotal support for high-dose epinephrine in cardiac arrest. At the same time, the first of his series of articles on the Ottawa Ankle Rules began to appear and with them a new standard for the development of clinical decision rules in medicine was established. In

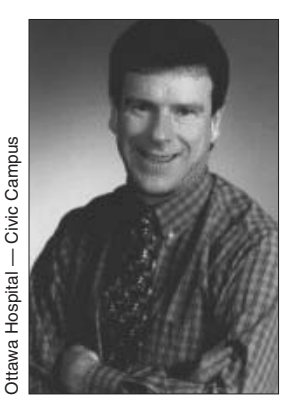

Dr. Ian Stiell idemiology fellowship training program and has supervised 9 Masters students. This year Ian received the Hal Jayne Academic Achievement Award from the Society for Academic Emergency Medicine and became the first Full Professor in the Division of Emergency Medicine at the University of Ottawa.

Always a team player, Ian's award reflects well on his emergency medicine colleagues at the University of Ottawa, who can no longer even glance at a patient without completing a data collection form, and on emergency physicians across the country who have been the 1995 he became a Career Scientist of the Medical Research Council of Canada and in 1996, a Senior Principal Investigator at the Loeb Health Research Institute's Clinical Epidemiology Unit, at the University of Ottawa. Research and publications continued on the Ottawa Knee Rules, active compression-decompression CPR, the Ontario Prehospital Advanced Life Support (OPALS) study, the Canadian $\mathrm{C}$-spine and CT rules among many, many others. He has been instrumental in developing Canada's first combined emergency medicine FRCPC-MSc epbackbone of so many of his multicentre clinical research projects.

Congratulations Ian, new Member of the Institute of Medicine of the National Academy of Sciences. The Canadian emergency medicine community salutes you and is incredibly proud of your achievements.

Acknowledgements: Thanks to Dr. Jan Ahuja, a temporary of Ian, for their valuable assistance.

Garth Dickinson, MD

Associate Editor, CJEM long time friend and colleague of Ian and Dr. Brian Rowe, a former student and current academic con- 